\title{
Terrorismo y espacios de la perpetración*
}

\author{
Prof. Luis VERES, PhD \\ Universidad de Valencia, Spain \\ E-mail: casa281068@yahoo.es
}

\begin{abstract}
Resumen. En la consideración del terrorismo como masacre política hay un campo a menudo poco estudiado como es el del espacio. A la hora de estudiar el terrorismo el análisis suele encaminarse hacia la figura del perpetrador, su naturaleza, sus móviles, ideologías, psicología, etc., o bien se centra en la víctima en los antecedentes, razones para erigirse en víctima, su reconocimiento o los aspectos colaterales del fenómeno victimario. El espacio suele quedar al margen. Pero el espacio no deja de constituir en un atentado en un elemento esencial de un enunciado. Este trabajo trata de aclarar la funcionalidad del espacio en el terrorismo entendido como comunicación desde una perspectiva histórica.
\end{abstract}

\section{Terrorism and Perpetration Spaces}

Abstract. In the consideration of terrorism as a political massacre, there is a field often little studied, such as space. When studying terrorism, the analysis is usually directed towards the figure of the perpetrator, his nature, his motives, ideologies, psychology, etc., or he focuses on the victim in the background, reasons to become a victim, his recognition or the collateral aspects of the victimizing phenomenon. The space is usually left out. But space does not cease to constitute an attack on an essential element of a statement. This work tries to clarify the functionality of space in terrorism understood as communication from a historical perspective.

Keywords: Terrorism; Perpetration space; Historical perspective.

* Este trabajo forma parte de dos proyectos: el proyecto financiado por la Conselleria de Educación, Investigación, Cultura y Deporte. AICO/2018/136 "Figuras de perpetradores de violencias de masas: relatos e imágenes", dirigido por Brigitte Jirku; y el proyecto "Representaciones contemporáneas del perpetrador de violencias de masas: conceptos, relatos e imágenes" dirigido por Vicente Sánchez-Biosca y Anacleto Ferrer financiado por el Ministerio de Ciencia y Tecnología. HAR2017-83519-P B 


\section{Introducción.}

En la consideración del terrorismo como masacre política hay un campo a menudo poco estudiado como es el del espacio. A la hora de estudiar el terrorismo el análisis suele encaminarse hacia la figura del perpetrador, su naturaleza, sus móviles, ideologías, psicología, etc., o bien se centra en la víctima en los antecedentes, razones para erigirse en víctima, su reconocimiento o la colateralidad del fenómeno victimario. El espacio suele quedar al margen. Pero el espacio no deja de constituir en un atentado en un elemento esencial de un enunciado. Este trabajo trata de aclarar la funcionalidad del espacio en el terrorismo entendido como comunicación.

Uno de los mayores logros de la pragmática textual está, a mi juicio en la obra de Oswald Ducrot Decir y no decir (1982), en donde apunta a la idea de que en un enunciado no hay ningún enunciado casual. Todo lo que se enuncia se enuncia por una razón. De ahí formula lo que él denomina "implícitos de la enunciación" formados por las razones que nos mueven a enunciar algo. Nadie enuncia por capricho. Si trasladamos esta idea al fenómeno del terrorismo podemos destacar el carácter simbólico que tiene todo atentado. No hay atentado casual y no hay objetivo casual. Tampoco hay espacio casual. Leontiev, discípulo de Vigotsky, señalaba que todo enunciado tiene una intención y unos resultados, (Bernárdez, 1982, 64), y ello se ve claramente en el hecho terrorista. Es más lo que diferencia al terrorismo de cualquier otra violencia política es su componente comunicativo. El perpetrador terrorista posee una serie de características que lo diferencia de cualquier otro criminal, ya que su naturaleza se fundamenta en la reivindicación. La mayoría de los delincuentes esconden sus actos, recurren a alias para no ser conocidos. El perpetrador terrorista llama por teléfono a un periódico para que anuncie su autoría, cuelga vídeos en Internet para propagar su mensaje y atribuirse ese crimen, envía comunicados a la prensa para explicar sus acciones. El mal llamado "terrorismo de Estado" responde a una lógica diferente: intenta ocultar sus acciones de inteligencia, sus operaciones encubiertas, pero no intenta propagar la autoría de sus actos. Ni la Dina en Chile ni las atrocidades realizadas en la Escuela de la Marina en Argentina, ni las torturas del cuartel de Intxaurrondo se realizaron para ser propagadas en los periódicos. Todo lo contrario. Y lo mismo se da en la mayoría de los hechos criminales vinculados a la violencia política. Pero, en el caso del terrorismo, como señalaba Sánchez Ferlosio, las muertes provocadas por los terroristas son "muertes firmadas" $(1982,79)$, según una estrategia previa de carácter político planificada y prolongada durante un espacio de tiempo largo.

\section{Terrorismo y pragmática.}

Estos hechos tienen su relevancia porque la signicidad de la realidad se extiende a los hechos del terrorismo a la hora de valorar tanto al perpetrador como a la vícti- 
ma. Roland Barthes fue el primero en considerar la realidad como el imperio de los signos al señalar que se podía estudiar en términos sígnicos todo. Del mismo modo, un amigo suyo, Algirdas Greimas (1973; 1980), indicó que todo discurso se producía por generación y por narración, respondiendo a la estrategia de una idea implícita y elemental sobre la que se construía una estructura narrativa. Si tenemos en cuenta estas formulaciones en relación con el terrorismo, los atentados responden a una idea elemental que es la necesidad de suscitar inseguridad, terror, con el fin de acorralar al Estado o conseguir una serie de contraprestaciones en un conflicto a todas luces asimétrico en cuanto a lo que las fuerzas se refiere. Como señala Portinaro, el terrorismo busca "un enorme guetto de inseguridad" (2017, 203). Y esos hechos significan un relato, una estructura narrativa que se da como entregas de una telenovela, pero de manera implícita. El terrorismo tiene carácter discursivo. Hay casos en donde este carácter episódico es evidente: Juegos Olímpicos de Munich en 1972, el asesinato de Carrero Blanco en 1973, el secuestro y asesinato de Aldo Moro por las Brigadas Rojas en 1979 (Veres, 2018), el 11 de Septiembre de 2001, la muerte de Bin Laden en 2011, etc., casos todos ellos llevados al cine por su propia narratividad. En todos los ejemplos las entregas se suceden en prensa, televisión e internet como un eco de lo noticioso. El caso de Miguel Ángel Blanco, asesinado a manos de ETA el 10 de julio de 1997, es paradigmático. Se le dispara a la cabeza con una bala de poco calibre, no el 9 milímetros parabellum con el que acostumbraba ETA a matar a sus víctimas, $5 \mathrm{~mm}$, y ello con el fin de prolongar su agonía y prolongar el relato. Se anuncia dónde se encuentra el cuerpo, una cuneta. La policía llega y todavía está vivo. Es conducido al Hospital más cercano en donde entra cadáver. Todo el país en vilo, tras un día de manifestaciones. Toda una trama narrativa.

Al mismo tiempo, como todo acto designativo, el terrorismo no deja de ser una construcción social mediante el lenguaje y mediante la selección de imágenes. Ya en los años sesenta P. Berger y T. Luckmann (1968) destacaron al discurso periodístico como un elemento clave de la construcción social de la realidad. De esa manera, el lenguaje aparece como el discurso generador de contenidos simbólicos que contribuyen a estructurar nuestra visión del mundo. Por ello, ese intento de suscitar el pánico en el seno social es muy limitado sin el acompañamiento de los medios. Al Qaeda consiguió la atención de todas las cadenas de televisión perpetrando el atentado más espectacular de la historia. Como señala Gil Calvo, el miedo es el mensaje (2003) y, de ese modo, la violencia provoca el espectáculo mediático que los medios desean y el terrorismo consigue la plataforma propagandística necesaria para sus fines (Veres, 2017). Estas ansias de exhibición propias del fenómeno terrorista han propiciado que se compare el terrorismo con el teatro, porque el terrorismo es un teatro con mensaje.

"El terrorista está actuando delante de un público. Las comunicaciones instantáneas han convertido al mundo entero en un anfiteatro, y en su sangrienta arena 
los gladiadores del emperador combaten con representantes de los sometidos del imperio que se han elegido a sí mismos. A menos que la multitud -en este caso los medios internacionales- se haya conmovido por el patriotismo sediento de sangre, no hay probabilidad de que vuelva los pulgares hacia abajo para condenar a las víctimas cuando los esbirros a sueldo, bien entrenados y mejor armados, entren a matar. El terrorista, que reconoce esto, sabe que le conviene ser considerado perdedor, y hasta rendirse en algunas batallas contra fuerzas superiores" (Schreiber, 1980, 88).

El terrorismo no deja de jugar con la idea del ritual, un ritual en imágenes que forma parte de la sustitución de lo real y que, sin esas imágenes, carece de virtualidad (Baudrillard, 2000,127). El terrorismo juega con la idea del miedo, con el tabú, con el imaginario que suscita un posible empeoramiento de la muerte (Delpierre, 1974, 15). Y ese miedo viene dado por su presencia en los medios. Al igual que las religiones, en donde el sacerdote amenaza con los males del infierno si no se entra en la fe (Catalán, 2019), el terrorismo señala que en el futuro tú puedes ser la víctima si no claudicas a sus peticiones. La estrategia del miedo es la tónica dominante, lo que Ulrich Beck ha llamado "el desconocimiento de la futura tasa de riesgos" (Beck, 2002), situación que suscita incertidumbre y el miedo al futuro. El siglo XX acabó con la confirmación de los miedos, El siglo XXI será el siglo de los miedos, porque nada va a ser mejor: fanatismos, sobrepoblación, problemas interculturales, senectud, inmigración y nuevos fascismos. El terrorismo real responde a ese efecto que produce el miedo en todos nosotros. Como señala Gil Calvo, "así es como los medios se convierten sin querer en bomberos pirómanos, pues la publicidad del riesgo percibido contribuye a magnificarlo" (Gil Calvo, 2003, 39). Y ese carácter ritual, mítico, es el que se da en el terrorismo suicida. La autoimolación se produce con cinturones explosivos de manera ritual y supone un sacrificio religioso, un espectáculo (Asad, 2008, 60). Y el espacio forma parte de ese ritual. Es el fondo de la escena.

\section{Terrorismo y biopolítica.}

La creación de ese miedo pasa por una violencia histórica: la transgresión de los espacios y de los cuerpos sin el apoyo de los estados o de las mayorías. De la misma manera han actuado Al-Queda y otros grupos, aunque se trate de atentados indiscriminados como los del 11-S o el del Hipercor de Barcelona, Las Ramblas en 2017, Atocha en 2004, las Torres Gemelas o el Puente de Vallecas suponen significaciones variadas, pero que tienen en común el simbolismo del poder sobre el espacio y los cuerpos. Porque ese dominio de la calle, que es propiedad comunal, se anula, y esa significación adquiere el objeto de hacer pensar a otras personas de semejantes características "mañana te puede ocurrir aquí" (Alonso-Fernández, 2002, 32). El terrorismo expulsa a los sujetos del ámbito urbano o rural. 
Del mismo modo se atenta contra los cuerpos que son parte de ese espacio. Agambem señalaba, al analizar el nazismo, que "únicamente en un horizonte bio-político se podrá decidir, en rigor, las categorías sobre las que se ha fundado la política moderna" (Agambem, 2003, 13). Por ello los cuerpos son política y también es el espacio. Y los cuerpos no son todos iguales, sino que cada identidad adquiere un valor simbólico por sí mismo, pero también por su naturaleza de carácter político ante la muerte y ante su repercusión mediática. Como señalaba Roland Barthes, al hablar del asesinato, "si es político, es una información, si no lo es, es un suceso" (Barthes, 1964, 188), porque el asesinato político necesita un campo de definición y una amplitud definitoria más amplia que el del asesinato corriente. Una nueva esfera de significación, por tanto, aúna nuevos sentidos al significado primario del crimen en sí, esfera formada por el contexto social e histórico, por la situación del conflicto y sus protagonistas, por sus antecedentes y sus consecuencias. Todo ello está ausente en el asesinato del delincuente ordinario (Veres, 2017). Pero también es cierto que las muertes tienen significado simbólico: de Kennedy o Luther King, de Gandhi a Gregorio Ordóñez, Fernando Buesa o Miguel Ángel Blanco. Aldo Moro, en Italia, en 1978, fue elegido como víctima por su signicidad, por el hecho de ser la bisagra que podía unir al partido comunista en Italia y a la Democracia Cristiana, lo cual dejaba sin campo de actuación a las Brigadas Rojas y la izquierda extraparlamentaria (Veres, 2018). Yoyes, miembro de ETA-m, fue asesinada por ETA delante de su hija en la plaza de su pueblo, Villafranca de Ordicia, por ser un miembro representativo de la banda que había decidido acogerse a las medidas de reinserción acordadas por el gobierno de Felipe González y abandonar la lucha armada. Y la víctima se contagia por metonimia por contigüidad de la significación del espacio y el espacio de la significación de las víctimas. Los ocupantes del World Trade Center pasaban a ser, de simples ciudadanos, a agentes del imperialismo económico norteamericano a ojos de sus prepetradores. Los trabajadores del Pentágono en Washington se revestían de la significación militar a pesar de que un gran número de ellos fueran civiles ajenos al ejército. De las 23,000 personas que figuran como personal unos tres mil no pertenecen al estamento militar.

Esa apertura de la significación y su revestimiento simbólico abarca notablemente el espacio de la perpetración que se constituye como el escenario del espectáculo. Atocha, por ejemplo, es un espacio en el que todo el que visite Madrid pasa en algún momento. Un lugar reconocible. Su cercanía a museos como El Prado o el Museo Reina Sofía obligan a su visita. Muchos de los que visitan Madrid tienen esa primera imagen de la ciudad. Lo mismo se daba con el centro de Nueva York y el World Trade Center, en las Ramblas de Barcelona, en el Hotel de Bali. Se trata de lugares visitados, frecuentados, ineludibles, cuya visita es memorable y obligatoria para el visitante y que, además reúne un gran número de residentes. Además su reconocimiento como espacio visitable facilita su presencia en los medios cuando 
la atrocidad se aparece. De ese modo el espacio se reviste de un nuevo sentido. El terrorismo resemantiza el espacio, incluso a veces lo modifica. El caso del cuartel de Intxaurrondo sería un ejemplo de este reasignación de sentido. Esa consideración del espacio lo asemeja al concepto de "no lugares" designado así por Augé, o al menos a lo que denomina "universos de reconocimiento" pues "lo propio de los universos simbólicos es constituir para los hombres que los han recibido como herencia un medio de reconocimiento, más que de conocimiento: universo cerrado en donde todo constituye signo" (Augé, 2000, 39).

Ese revestimiento simbólico del espacio se produce antes y después de la violencia. A veces el espacio posee una carga simbólica en sí. La Cafetería Rolando de Madrid era frecuentada por policías que trabajaban en la Dirección General de Seguridad en la Puerta del Sol. Una bomba explotó en septiembre de 1974 causando trece muertos y un centenar de heridos. El Pentágono tiene connotaciones evidentemente militares y el World Trade Center implicaciones económicas. La Casa de España en Casablanca en 2003 tiene referencias coloniales. Casi todos los espacios de atentados atraen el terrorismo por su eco mediático, su utilidad a la hora de causar víctimas: Aeropuerto de Bruselas, Estación de Atocha, Estación de Bolonia, Banca de la Agricultura de Milán, el Parlamento de Londres, la maratón de Boston.

Esta consideración supone que su elección es premeditada ya que confiere sentido al atentado ya que lo convierte en noticioso y en memorable. Pierre Nora en el prefacio a su primer volumen de Lugares de la memoria, habla de espacios en donde se acumulan testimonios imágenes, "signos visibles de lo que fue", una luz sobre lo que fue y ya no es que se culmina con los memoriales posteriores como la zona Cero de Nueva York, el memorial de Atocha, la placa conmemorativa de los asesinatos de los abogados laboralistas en 1977, el monumento a Fernando Buesa en Vitoria, etc., todos ellos lugares que plasman "una metáfora de la historia conflictiva de la nación" (Winter, 2006, 13). Y la estrategia terrorista se fija en este aspecto. La sede de Charlie Hebdo en 2015 era un cenáculo de la libertad de prensa y del modo de vida occidental, elementos repudiados por el yihadismo, espacio que fue resemantizado a partir de la crítica despiadada, en el mundo islamista, de sus caricaturas sobre el islamismo y el posterior atentado. El espacio amplió notablemente su esfera de significación. El paseo marítimo de Niza constituía el espacio de la burguesía tradicional desde principios del S.XX como inmortalizó Jean Vigo en 1930 y que ha modificado su percepción para mucho franceses. Todos los aeropuertros del mundo se han modificado tras los atentados del 11 de septiembre. Hemos modificado el espacio y nuestros hábitos a la hora de viajar en avión. El terrorismo ha trasformado nuestra sensibilidad. Ya no vemos a un árabe igual, pues los atentados han hecho funcionar lo que Leech denominaba el "significado reflejo". 
La estrategia del terrorismo no responde siempre a matar a alguien en concreto. A veces sí, como vemos, cuerpos concretos, significados concretos, pero con esta estrategia muchas veces no importa la derrota física de la víctima, sino la creación de un clima de inseguridad y miedo que puede poner de relieve la ineficacia o impotencia del Estado y que puede facilitar, o no, la consecución de sus pretensiones: cesión de un territorio, liberación de presos, reivindicaciones nacionalistas o religiosas, etc. De ahí surgen las matanzas indiscriminadas en espacios públicos sin importar las víctimas. Hacer temblar el suelo en el que basamos nuestra seguridad. En el 11-M murieron muchos musulmanes que son las principales víctimas en los atentados yihadistas. ETA ha atentado contra vascos nacionalistas y las Brigadas Rojas asesinaron al líder sindical comunista Guido Rossa. Frederick J. Hacker, psiquiatra y especialista en terrorismo, señaló que lo que quieren los terroristas es impresionar: "Ellos actúan con y para el público y solicitan su participación" (1976, XI). Y lo cierto es que la historia del terrorismo abala esta realidad. En 1985, un grupo de Hezbolá y Yihad Islámica secuestró un avión de la compañía TWA que viajaba de El Cairo a Los Ángeles. Sus perpetradores comunicaron que no les interesaba ningún periodista que no fuera norteamericano ni que no trabajara para una cadena de televisión (Laqueur, 1987, 125; 2003). Lo mismo se había dado con el atentado del hotel King David en 1947. La Irgún, organización anticolonial contra Inglaterra que buscaba la creación del estado de Israel, colocó una bomba en el hotel King David en donde se alejaban oficiales británicos. Las fotografías aparecieron en todos los diarios británicos. En septiembre de ese año, Arthur Creech-Jones anunció la retirada de su gobierno de territorio palestino y el 15 de mayo de 1948 se proclamaba oficialmente el Estado de Israel.

Esta actitud, que dio un vuelco en el desarrollo y estrategias del terrorismo, se vio ayudada por los avances tecnológicos de la época que suponían un gran adelanto en la grabación y transmisión de imágenes, con lo cual las noticias y los acontecimientos podían ser difundidos con mayor rapidez a mucha más gente y en muchos más países. El terrorismo no tardó mucho en darse cuenta de que ésta era la mejor vía de escape para sus actuaciones. Lo mismo sucedió en los Juegos Olímpicos de Munich. El 5 de septiembre de 1972, ocho encapuchados pertenecientes a una facción de la OLP denominada Septiembre Negro (OSN) entraron en los dormitorios de los atletas olímpicos de la delegación de Israel. Fueron asesinados dos de ellos y se tomaron como rehenes otros nueve. El desenlace fue fatídico para los miembros de Septiembre Negro que fueron abatidos en el aeropuerto.

Aparentemente, los terroristas habían fracasado, pero Septiembre Negro consiguió durante muchas horas llenar las parrillas televisivas con una audiencia muy superior al resto de noticias emitidas en ese espacio de tiempo: cuatro mil periodistas de prensa y radio y dos mil reporteros de televisión que se habían desplazado a Munich para cubrir el acontecimiento olímpico, no informaron sobre los juegos, 
sino sobre las operaciones de Septiembre Negro. Se calcula que la cuarta parte de la población mundial se enteró del acontecimiento. Y todo era una usurpación del espacio público que lograba fácilmente convertirse en noticia.

En España el 29 de octubre de 1988 ETA liberó al industrial Emiliano Revilla después de 249 días de cautiverio y tras cobrar cerca de 1200 millones de pesetas como rescate. La información periodística originada a partir del secuestro de Revilla supuso para ETA una propaganda que si hubiese sido pagada hubiera costado más de 15,000 millones de pesetas. El terrorismo es como una gigantesca maquinaria publicitaria.

En realidad, lo que sí parece evidente es que el terrorismo guarda una estrecha relación con los medios de comunicación y el peligro de esa estrecha relación, que medios de comunicación y terrorismo mantienen, es la certeza de que ese vínculo supone una especie de "simbiosis". Wilkinson ha señalado que "cuanto más horribles los crímenes de los terroristas, mayores serán los titulares” y ello afecta a la elección del espacio (Aguilar, 1982, 152). Esta dependencia ha conducido a algunos teóricos a afirmar que, si no existiesen los medios de comunicación, no existiría el terrorismo, ya que "si no hubiera medios masivos, no se producirían esos actos destinados a ser noticia” (Eco, 1986, 150-156). Marshall McLuhan era mucho más tajante cuando afirmaba que "sin comunicación no habría terrorismo" (McLuhan, 1978), lo cual les lleva a pensar que el terrorismo es algo consustancial al mundo moderno. Y es cierto que el 11 de septiembre existió para que pudiera ser visto por televisión.

Este ataque a lo social supone la aparición en el fenómeno del terrorismo del cuerpo como elemento de cambio, como elemento indiscriminado que forma parte de las mayorías silenciosas en donde no se separa "a los verdugos de las víctimas" $(1987,162)$. El terrorismo se fundamenta en la violencia indiscriminada a veces mediante atentados masivos - recientes como 11-S, 11-M, Bostón, Mali, o atentados lejanos en el tiempo como el de de Piazza Fontana en Milán, Estación de Bolognia, casa cuartel de Vich, el centro comercial Hipercor de Barcelona, etc.

"Eso es el terrorismo, no es original e insoluble, más que porque golpea no importa dónde, no importa cuándo, no importa a quién, si no no sería más que secuestro con rescate o acción de comando militar. Su encegamiento es la exacta réplica de la indiferenciación absoluta del sistema, que desde hace mucho tiempo ya no separa los fines de los medios, a los verdugos de las víctimas, Su acción apunta, en la indistinción asesina de la toma de rehenes, precisamente al producto más característico de todo el sistemas: el individuo anónimo y perfectamente indiferenciado, el termino insustituible por cualquier otro. Hay que decir paradójicamente: los inocentes pagan el crimen de no ser nada, de ser sin destino, de haber sido desposeídos de su nombre por un sistema también anónimo del cual son entonces la encarnación más pura. Son los productos finitos de lo social, de una sociali- 
dad abstracta a partir de ahora mundializada. En este sentido, en el sentido justamente en el que son cualesquiera, que son víctimas predestinadas del terrorismo." (Baudrillard, 1982, 162)

Baudrillard tuvo en cuenta el anonimato de los cuerpos en los atentados masivos, pero no el valor de los cuerpos en asesinatos con un objetivo personal o simbólico. Foucault a partir de la noción de biopolítica ha recogido este valor de los cuerpos como punto de poder que reconduce y resguarda el poder. El cuerpo, como formulación de poder, sugiere un valor simbólico y un valor de cambio que en el fenómeno terrorista adquiere una significación especialmente importante. La signicidad de la realidad se extiende a los hechos del terrorismo a la hora de valorar tanto al perpetrador como a la víctima. Como señala Foucault, el poder "es lo que dice no" (Foucault, 1982, 80). No a la circulación de los cuerpos, no al espacio público, no a las vidas, no a la unicidad del cuerpo. Los cuerpos son esenciales en los secuestros, en los asesinatos, en los casos de acoso, desde los inicios del terrorismo, y los cuerpos son de vital importancia en atentados, especialmente en el terrorismo yihadista de los últimos años. Incluso las partes del cuerpo adquieren una significación concreta: los partisanos italianos disparaban a las piernas de sus enemigos como reprimenda, técnica que recuperaron las Brigadas Rojas y miembros de Autonomia Operaia en la Universidad de Padua a finales de los setenta (Naccarato, 2008; Panvini, 2009; Ventura, 2010; Panvini, 2009; 2011; Volpe, 2013; Re, 2013). Los desollamientos trasmitidos en video por grupos afines a Al Qaeda y por miembros del DAESH también adquieren esa significación concreta de repudio al enemigo como comenzó a perpetrar Al Qaeda en 2004 con el asesinato de Nick Berg (Veres, 2017).

Así el terrorismo y su historia muestran numerosos ejemplos de esta circunstancia. El más evidente es el asesinato personal como transgresión máxima de la violencia contra el cuerpo. Muchos casos de terrorismo han optado por la exclusión del cuerpo en la calles: la marginación de la víctima. Noelle Newmann habló de la espiral del silencio para aquellas situaciones en que el sujeto queda aislado por sus opiniones desde el punto de vista comunicativo. Esa estrategia se fundamenta en la exclusión de personas en determinados espacios. Los estados de guerra favorecen frecuentemente estos procesos: desde el genocidio armenio a los diferentes progrom contra los judíos o la limpieza étnica en Bosnia, desde la guerra civil española al actual conflicto entre Palestina e Israel. En una proporción menor, a lo largo de cincuenta años aproximadamente, la marginación de ciudadanos en el País Vasco formó parte de la estrategia de ETA al apropiarse de la calle mediante la Kale Borroca o lucha callejera. Muchos ciudadanos del País Vasco fueron obligados al exilio tras amenazas y exigencia del pago del impuesto revolucionario. Portinaro, siguiendo a Lemkin y quitándole protagonismo al Estado (1944) define el genocidio como "plan coordinado de diferentes acciones dirigido a la destrucción 
de los fundamentos de la vida de un grupo nacional con el objetivo de aniquilarlos" (2017:30). Goldhagen hablaría de un "ataque eliminacionista" (2010:18) o lo que Barth llamaría un "genocidio indirecto" (Portinaro, 2017, 34). El aislamiento y el reconocimiento del sujeto como no perteneciente a la causa suponían una exclusión progresiva, basada en lo étnico, racial o la vinculación política, como se detalla en la novela Patria de Fernando Aramburu y que ponen de manifiesto algunos testimonios. Del mismo modo la ultraderecha española se apropió de las calles en los primeros meses de la Transición democrática mediante atentados parapoliciales y acciones intimidatorias contra ciudadanos corrientes Casals, 2016, 16).

Alan Wolf ha señalado que este tipo de apropiación que conduce a la limpieza étnica es una de las formas más importantes de la maldad política: "La limpieza étnica es la segunda forma de maldad política que hay que señalar”. Para Norman Naimark, al que cita Wolf, esta limpieza consiste en borrar a determinadas personas de un territorio y eliminar cualquier rastro de ellas. El objetivo es librarse de estas personas y hacerse con el poder en el territorio que antes ocupaban (2012, 36). Este tipo de eliminación del sujeto se intentó realizar en Irlanda, en Palestina, en Bosnia, en los territorios europeos en donde se dio la Soah, en el Chile indígena habitado por el pueblo mapuche, en Irlanda, en el País Vasco, en algunas ciudades italianas durante los años setenta. Y detrás de todo ello, según Michael Mann, muchas veces se mantiene una radicalización del nacionalismo o del etnocentrismo en donde la raza se impuso a la clase (Mann, 2004, 107). Christian Scherrer señala fases en el desarrollo de una tanatopolítica que conduce a su fase final que es el genocidio. Entre esas fases se incluye el reconocimiento, el aislamiento de la víctima, su deshumanización, el control y la atrocidad antes de su exterminio parcial $(2005,8)$.

Claro efecto del terrorismo fue la búsqueda de la eliminación o exclusión progresiva de una parte de los habitantes del País Vasco a partir de una interpretación de las ideas de Sabino Arana. Al principio se trató de objetivos concretos como Melitón Manzanas o destacadas autoridades militares como el segundo de Franco, Luis Carrero Blanco, pero con la llegada de la democracia los objetivos se volvieron indiscriminados, apostando por las grandes matanzas que lograban su repercusión en los medios. Las víctimas eran elegidas o bien por su significación y relevancia mediática o bien mediante lo que Girard denominó "una transferencia de la culpabilidad" (Girard, 2002, 206). Se atacaba a otros por pecados que nunca eran atribuibles a nosotros, es decir, el otro era el responsable de nuestra violencia y siempre había un motivo para despersonalizar al adversario. "Algo habrán hecho", se rezaba en el País Vasco ante el simple hecho de ocupar el territorio (Sáez de la Fuente y Prieto, 2017, 36). Por ello la violencia era justificable en determinado espacio y tiempo.

En el Perú de Sendero Luminoso en los años ochenta muchos campesinos eran reclutados y obligados a participar en la lucha armada, como bien ejemplifica la 
película Paloma de papel (2003) de Fabrizio Aguilar, para robar y asesinar a otros de la misma condición o bien meramente expulsarlos de su aldea para apropiarse de todo. Ciudadanos del país vasco, desde profesores de universidad como Francisco Llera o empresarios de éxito, o militares, policías, ciudadanos de a pie, fueron obligados a abandonar su residencia como consecuencia de ese proceso de exclusión del otro, del diferente. Los senderistas se apropiaban de Lima y significaban su presencia mediante hogueras que dibujaban la hoz y el martillo signos de la lucha comunista o colgaban perros ahorcados en las avenidas del centro de Lima para indicar que Sendero Luminoso estaba cerca en su propósito de guerra al Estado mediante el equilibrio estratégico. ETA o el IRA crearon toda una estética callejera de banderas, proclamas, pintadas, lemas e imágenes de terroristas que significaban el dominio del territorio. La apropiación del espacio resultaba de este modo fundamental en la estrategia terrorista, y cuanto mayor sea, mayor es el logro. "Bombas por todas partes" rezaba en los setenta un panfleto de la organización terrorista ORMICA de carácter antifranquista que era conocida como "la ETA catalana" (Casals, 2016, 148).

El caso más sangrante sobre la presión ejercida para que los otros abandonen el territorio es el de Pilar Elías, una viuda residente en Azkoitia, cuyo marido, Ramón Baglietto, es asesinado por ETA el 13 de mayo de 1980. Su verdugo es Kandido Azpiazu, concenado a 15 años (Domínguez, 2012, 303). Baglietto se presentaba a las elecciones municipales en un contexto en que tres concejales del PP habían sido asesinados en un mes. La hermana de la víctima, Nieves Baglietto, estuvo recibiendo amenazas telefónicas para que abandonase el territorio: "Si no quieres ser la próxima, vete de Euskadi”. Veinticinco años después Kandido Azpiazu compró la cristalería situada junto al patio del domicilio de Pilar Elias, sin que la ley hiciera algo para evitarlo ${ }^{1}$.

Muchos grupos terroristas se han apoyado en un partido político que reivindicaba en manifestaciones en la calle sus exigencias y hacía público sus proclamas y banderas. Y eso era un intento de apropiación del espacio apoyándose en la legalidad. Autonomía Operaia se adueñó de la ciudad de Padua a finales de los setenta mediante enfrentamientos en la calle, asalto a comercios y ataques a profesores de la universidad a finales de los setenta (Naccarato, 2008: Ventura, 2010; Petter, 2011; Volpe, 2013; Re, 2013; Veres, 2018). ETA y Batasuna dominaron la calle en los años noventa (Fernández Soldevilla y López Romo, 2012, 145) y organizaron una infraestructura que se hizo con gran parte del espacio público. La exclusión del contrario llevó a un dominio de todo espacio al llegar a ser el único segmento social de izquierda con presencia en ciudades y pueblos mediante marchas por la paz que eran

\footnotetext{
1 https://elpais.com/diario/2005/12/04/espana/1133650812_850215.html.
} 
elogios de la violencia y homenajes a presos de ETA y asesinos huidos:

"El entramado civil de la banda se fue ampliando posteriormente con la aparición o apropiación de empresas deportivas, educativas y culturales (determinadas ikastolas, academias de enseñanza del Euskera, editoriales, sellos discográficos, radios, etc.), su expansión en el mundo asociativo, su influencia en la universidad, una extensa red de herrico tabernas (tabernas del pueblo), la promoción del rock radical vasco, el cuasi monopolio de las fiestas populares, etc. Apareció entonces una sociedad dentro de la sociedad, con su propia cultura, sus redes sociales, sus medios de comunicación, sus lugares de ocio, sus rituales, su vestimenta, sus claves internas, su argot, etc. En definitiva, se trataba de una comunidad incivil." (Fernández Soldevilla y López Romo, 2012, 145).

El Sinn Féin controlaba la ciudad de Belfast en los ochenta. Brigadas Rojas en compañía de Autonomía Operaia se apropió de muchas factorías de Milán, Torino, Padua, Marghera, etc. a finales de los setenta. Daesh fue más lejos y se apropió de gran parte del territorio sirio eliminado todo lo que no tenía que ver con ellos. Homenajes en la calle, celebraciones con banderas, pintadas, perros muertos colgados en las farolas suponen la apropiación del espacio y la exclusión de los sujetos que en muchos casos comportan una discriminación racial, social o política. La falta de condena de la violencia y una memoria igualadora de todas las víctimas también conducen a esta exclusión y a evitar el perdón (Mate, 2008, 41; López Romo, 2015, 117). Y eso se hizo con un apoyo explícito si no a la violencia del terrorismo a lo que el terrorismo representaba. El apoyo de parte de la población en casi todos los casos fue definitivo para el control del espacio. Desde la designación del enemigo como maketo a proclamas como "para amar el euskera, tenéis que odiar a España" (Fernández Soldevilla y López Romo, 2012, 43).

Muchos espacios se han convertido en lugares de la memoria y el terrorismo mediante su soporte en el espacio se ha confirmado como una estructura textual al igual que muchos lugares de la memoria, al igual que la desaparición de la mirada de la víctima que conduce a la exclusión (Mate, 2008, 42). Como se ve el espacio trasforma la historia en memoria, incluso en postmemoria (Zulo Ortega Lara, Patriotas Reinares).

\section{Bibliografía}

1. Agambem, Giorgio (2003). Homo sacer. El poder soberano y la nuda vida. Valencia: Pretextos.

2. Aguilar, Miguel Ángel (1982). La estrategia del desistimiento. Algunas observaciones sobre el caso español. En Reinares-Nestares, Fernando (Comp.), Terrorismo y sociedad democrática. Madrid: AKAL.

3. Alonso-Fernández, Francisco (2002). Fanáticos terroristas. Claves psicológicas y sociales del terrorismo. Barcelona: Salvat. 
4. Asad, T. (2008). Sobre el terrorismo suicida. Barcelona: Laertes.

5. Augé, Marc (2000). Los no lugares. Espacios del anonimato. Una antropología de la sobremodernidad. Barcelona: Gedisa.

6. Barthes, Roland (1964). Essais critiques. Paris: Seuil.

7. Baudrillard, Jean (1987). La precesión de los simulacros. En Cultura y simulacro. Barcelona: Kairós.

8. Baudrillard, Jean (2000). Pantalla total. Barcelona: Anagrama.

9. Beck, Ulrich (2002), La sociedad del riesgo global. Madrid: Siglo XXI.

10. Berger, Peter y Luckmann, Thomas (1968). La construcción social de la realidad. Buenos Aires: Amorrortu Editores.

11. Bernárdez, E. (1982). La lingüística del texto. Madrid: Espasa-Calpe.

12. Casals, Xavier (2016). La transición española. El voto ignorado de las armas. Barcelona: Pasado \& Presente.

13. Delpierre, G. (1974). Le peur et l'être. Toulouse.

14. Domínguez, Florencio (2012). La agonía de ETA. Madrid: La Esfera de los Libros.

15. Ducrot, Oswald (1982). Decir y no decir. Barcelona: Anagrama.

16. Eco, Umberto (1986). Golpear el corazón del Estado. En La estrategia de la ilusión. Barcelona: Lúmen.

17. Foucault, Michel (1995). Un diálogo sobre el poder. Madrid: Alianza Editorial.

18. Foucault, Michel (2013). Nascita de la biopolítica. Milán: Feltrinelli.

19. Girard, René, (2002). Veo a Satán caer como un relámpago. Barcelona: Anagrama.

20. Gil Calvo, Enrique (2003). El miedo es el mensaje. Riesgo, incertidumbre y medios de comunicación. Madrid: Alianza Editorial.

21. Goldhagen, Daniel Johan (2010). Peggio della guerra. Lo sterminio di masa nella storia dell'umanità. Milán: Mondadori.

22. Greimas, Aljirdas (1973). En torno al sentido. Ensayos semióticos. Madrid: Fragua.

23. Greimas, Aljirdas (1980). Semiótica y ciencias sociales. Madrid: Fragua.

24. Hacker, Frederick J. (1976). Crusaders, Criminals, Crazies: Terror and Terrorism in Our Time. New York: W.W. Norton.

25. Laqueur, Walter (1987). The Age of Terrorism. Boston: Brown.

26. Laqueur, Walter (2003). Una historia del terrorismo. Barcelona: Paidós.

27. López Romo, Raúl (2015). Informe Foronda. Los efectos del terrorismo en la sociedad vasca. Madrid: Libros de la Catarata.

28. Mann, Michael (2004). El lado oscuro de la democracia. Valencia: Publicaciones de la Universidad de Valencia.

29. Mate, Reyes (2008). Fusticia de las víctimas. Terrorismo, memoria, reconciliación. Barcelona: Anthropos.

30. Naccarato, Alessandro (2008). Violenze, eversione e terrorismo del partito armato a Padova. Università di Padova.

31. Panvini, Guido (2009). Ordine nero, guerrila rossa. Torino: Giulio Einaudi Editore.

32. Petter, Guido (2011). I giorni dell'ombra. Milán: L’Ornitorinco. 
33. Portinaro, Pier Paolo (2017). L'imperativo di uccidere. Roma: Laterza.

34. Re, Matteo (2013). Pertenencia a banda armada. Ataque al corazón del estado y terrorismo en Italia (1970-1988). Madrid: Biblioteca Nueva.

35. Sáez de la Fuente, Izaskun (Ed.), (2017). Misivas del terror. Madrid: Marcial Pons.

36. Sáez de la Fuente, Izaskun y Prieto, Jesús (2017). La extorsión como proceso social en un contexto de violencia terrorista. En Sáez de la FUente, Izaskun (Ed.), Misivas del terror. Madrid: Marcial Pons.

37. Sánchez Ferlosio, Rafael (1982). Notas sobre el terrorismo. En Reinares-Nestares, Fernando (Comp.), Terrorismo y sociedad democrática. Madrid.

38. Schreiber, Jan (1980). La última arma: terrorismo y orden mundial. Zaragoza: Trazo Editorial.

39. Scherrer, Christian (Ed.) (2005). Genocide and Mass Violence in the 20th and 21st Centuries. An Introdution: Critera, Common Elements, and Patterns. Moers: IFEK.

40. Ventura, Angelo (2010). Per una storia del terrorismo italiano. Roma: Donzelli.

41. Veres, Luis (2017). Los lenguajes del terrorismo. De ETA al ISIS. Valencia: Tirant lo Blanc.

42. Veres, Luis (2018). Las Brigadas Rojas y el cine. Valencia: Tirant lo Blanc.

43. Winter, Ulrich (2006). Introducción, En Ulrich Winter, Lugares de memoria de la Guerra Civil y el Franquismo. Madrid: Iberiamericana-Vervuert.

44. Wolf, Alan (2013). La maldad política. Barcelona: Galaxia Gutemberg. 